Projets

de paysage

\section{Projets de paysage}

Revue scientifique sur la conception et l'aménagement de l'espace

$8 \mid 2012$

Les concepteurs de jardins et de parcs japonais

\title{
Les paysages périurbains, des héritages à une gestion différenciée des territoires (seconde partie)
}

Présentation de la rubrique « Enquêts et débats »

\section{Sylvie Servain}

\section{(2) OpenEdition}

Journals

Édition électronique

URL : http://journals.openedition.org/paysage/14834

DOI : $10.4000 /$ paysage. 14834

ISSN : 1969-6124

Éditeur :

École nationale supérieure du paysage de Versailles-Marseille, Institut national des sciences appliquées Centre Val de Loire - École de la nature et du paysage, École nationale supérieure d'architecture et de paysage de Bordeaux, École nationale supérieure d'architecture et de paysage de Lille, Agrocampus Angers

\section{Référence électronique}

Sylvie Servain, « Les paysages périurbains, des héritages à une gestion différenciée des territoires (seconde partie) », Projets de paysage [En ligne], 8 | 2012, mis en ligne le 07 juillet 2012, consulté le 11 mars 2021. URL : http://journals.openedition.org/paysage/14834 ; DOI : https://doi.org/10.4000/ paysage. 14834

Ce document a été généré automatiquement le 11 mars 2021.

Projets de paysage 


\section{Les paysages périurbains, des héritages à une gestion différenciée des territoires (seconde partie)}

Présentation de la rubrique « Enquêts et débats »

\section{Sylvie Servain}

1 Cette seconde série d'articles fait suite à la rubrique « Enquêtes et débat » du numéro 7 de la revue. Il s'agit d'aborder les paysages périurbains et plus spécifiquement les échelles, les acteurs et les démarches qui peuvent donner lieu à de nouvelles productions paysagères.

2 Les articles proposés, qui s'appuient sur des terrains en France (île-de-France, pays nantais, métropole lilloise) et à l'étranger (Mexique, Wallonie, Roumanie), illustrent le développement de nouvelles fonctionnalités et la mise en place de politiques et d'outils, comme les zones agricoles protégées, dans une perspective de régulation de l'étalement urbain et de gestion économe des terres agricoles.

\section{AUTEUR}

\section{SYLVIE SERVAIN}

Sylvie Servain est professeure et géographe, département École de la nature et du paysage, Insa Centre Val de Loire, UMR 7324 Citeres (CNRS-université de Tours).

sylvie.servain[at]insa-cvl[dot]fr 